\title{
Acute Hemolytic Anemia in Glucose-6-Phosphate Dehydrogenase Deficiency Complicated by Ginkgo biloba
}

\author{
Shiue-Wei Lai ${ }^{\mathrm{a}} \quad$ Jia-Hong Chen ${ }^{\mathrm{a}}$ Woei-Yau Kao $^{\mathrm{a}, \mathrm{b}}$ \\ a Division of Hematology-Oncology, Department of Internal Medicine, Tri-Service General Hospital,

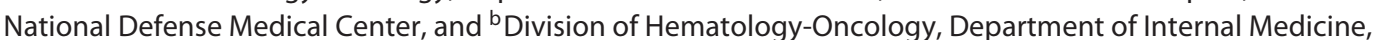 \\ Buddhist Tzu Chi General Hospital, Taipei Branch, Taipei, Taiwan, ROC
}

\section{Key Words}

Ginkgo biloba - Glucose-6-phosphate dehydrogenase deficiency $\cdot$ Hemolytic anemia

\begin{abstract}
We report on a patient with glucose-6-phosphate dehydrogenase (G6PD) deficiency who developed acute hemolytic anemia after having received an injection of Ginkgo biloba for dementia prophylaxis without medical advice. She suddenly developed general malaise, generalized yellowish skin color, and tea-colored urine. Intravenous fluid infusion and cessation of G. biloba quickly relieved her clinical symptoms. To the best of our knowledge, this is the first case report of G. biloba-induced acute hemolytic anemia in vivo.
\end{abstract}

๑) 2013 S. Karger AG, Basel

\section{Introduction}

Gingko biloba is the fourth most frequently used source of herbal medicine in the United States, accounting for $4.3 \%$ of all single herb sales in 2001 [1]. Its extract is used for many clinical conditions, including dementia, mild cognitive impairment, cerebrovascular and arterial insufficiency, tinnitus, vertigo, asthma, and allergies [2]. Nowadays, more people are frequently turning to herbal medicines as supplemental treatments for various medical conditions, often without medical advice. Increasing evidence suggests that $G$. biloba leaf extract can act as a prooxidant in vitro and in vivo. These extracts contain quercetin $[3,4]$ and procyanidins [5], which induce oxidative stress, especially in high doses.

We report on a patient with glucose-6-phosphate dehydrogenase (G6PD) deficiency who developed acute hemolytic anemia after having received an injection of G. biloba. A complete investigation revealed no other explanatory factors.

\section{Case Report}

A 55-year-old Chinese woman presented to the emergency department with generalized yellowish skin color, tea-colored urine, and epigastric pain. She also had experienced general malaise and headache for 2 days.

Her pertinent medical history included hypertension, for which she had been taking nifedipine ( $60 \mathrm{mg}$ twice daily), telmis$\operatorname{artan}(80 \mathrm{mg}$ daily), and atenolol ( $50 \mathrm{mg}$ daily) for more than 10 years. She had received a single injection of G. biloba leaf extract $(17.5 \mathrm{mg})$ by a licensed nurse in a local clinic for dementia prophylaxis 3 days before admission. Symptoms of general malaise and headache developed the next day. There were no other symptoms or adverse reactions, such as skin rash or stomach discomfort that could be traced from her history.

\section{KARGER}

E-Mail karger@karger.com

www.karger.com/aha
(C) 2013 S. Karger AG, Basel

$0001-5792 / 13 / 1304-0288 \$ 38.00 / 0$
Woei-Yau Kao, MD, PhD

Division of Hematology-Oncology, Department of Internal Medicine Tri-Service General Hospital, National Defense Medical Center No. 325, Section 2, Cheng-Kung Road, Neih, Taipei 114, Taiwan (ROC) E-Mail wykao@seed.net.tw 
She had no history or evidence of autoimmune disease and denied exposure to lead or other heavy metals, including G. biloba. She did not eat fava beans or take aspirin during or just prior to the 3 -day period before admission. No common infection-related symptoms of fever, chills, productive cough, abdominal discomfort or urinary irritation were found before admission. Her family history included a younger sister and niece with G6PD deficiency. She had not been previously diagnosed with this hereditary disease.

On admission, the patient's vital signs showed a temperature of $36.1^{\circ} \mathrm{C}$, a pulse of 81 beats/min, a respiratory rate of 26 breaths/ min, and blood pressure of 155/90 mm Hg. Physical examination revealed respiratory distress, pale conjunctiva, scleral icterus and generalized jaundice. There were no signs of jugular venous distention, enlarged thyroid gland, or lymphadenopathy. Her lungs were clear, her heart sounds were distinct without murmurs, and her abdomen was soft without masses or organomegaly. She had no rashes or peripheral edema. A neurological examination revealed mild lethargy but otherwise normal mental status, without focal findings.

Laboratory studies (table 1) indicated severe anemia, with a hemoglobin concentration of $5.5 \mathrm{~g} / \mathrm{dl}$ (normal: $11.3-15.3 \mathrm{~g} / \mathrm{dl}$ ). Her hemoglobin level had dropped from a previous baseline of $10.7 \mathrm{~g} /$ dl. G6PD deficiency was also found, with a level of $2.89 \mathrm{U} / 10^{12}$ erythrocytes (normal: 4.6-13.5 U/10 12 erythrocytes). Other significant findings included elevated lactate dehydrogenase (1,311 IU/l; normal: $135-225 \mathrm{IU} / \mathrm{l})$, decreased haptoglobin $(5.5 \mathrm{mg} / \mathrm{dl}$; normal: $30-200 \mathrm{mg} / \mathrm{dl})$, and increased total bilirubin $(4.7 \mathrm{mg} / \mathrm{dl}$; normal: $0.0-1.0 \mathrm{mg} / \mathrm{dl}$ ) with direct bilirubin $0.5 \mathrm{mg} / \mathrm{dl}$ (normal: $0-0.4$ $\mathrm{mg} / \mathrm{dl})$

Treatment included volume repletion and cessation of $G . b i$ loba administration. The hemoglobin level rose to $7.1 \mathrm{~g} / \mathrm{dl}$ from 5.5 $\mathrm{g} / \mathrm{dl}$, and the marked hyperbilirubinemia resolved (total bilirubin $0.5 \mathrm{mg} / \mathrm{dl}$; direct bilirubin $0.1 \mathrm{mg} / \mathrm{dl}$ ) after supportive treatment with intravenous hydration. She was discharged 5 days later without sequelae. On follow-up 2 weeks later, she was asymptomatic with a hemoglobin concentration of $10.1 \mathrm{~g} / \mathrm{dl}$.

\section{Discussion}

The major pharmacological substances in G. biloba leaf extracts are flavonoids, which are effective antioxidants and oxygen free-radical scavengers that confer the unique pharmacological properties of G. biloba.

Pawlikowska-Pawlega et al. [3] showed that quercetin has protective effects against hypotonic hemolysis and causes acceleration of the heat-induced hemolysis. Robaszkiewicz et al. [4] investigated concentration-dependent effects of quercetin on the human non-small lung cancer cells A549 in vitro, including augmentation of thiol content, total intracellular capacity at low quercetin concentrations, and a decrease at higher concentrations of the flavonoid (>50 mM). Shao et al. [5] reported that higher doses of grape seed proanthocyanidin extract (100 or $500 \mu \mathrm{g} / \mathrm{ml}$ ) could cause apoptotic cell injury and sub-
Table 1. Laboratory test results

\begin{tabular}{|c|c|c|c|c|}
\hline \multirow[t]{2}{*}{ Variable (reference range) } & \multicolumn{4}{|c|}{ Test results } \\
\hline & $\begin{array}{l}10 \text { days } \\
\text { before }\end{array}$ & $\begin{array}{l}\text { on ad- } \\
\text { mission }\end{array}$ & $\begin{array}{l}\text { day } \\
3\end{array}$ & $\begin{array}{l}\text { day } \\
14\end{array}$ \\
\hline Hemoglobin (women: $11.3-15.3$ ), g/dl & 10.7 & 5.5 & 7.1 & 10.1 \\
\hline Reticulocyte count $(0.5-1.5), \%$ & & 7.45 & & \\
\hline Platelets $(150-400), \times 10^{9} / 1$ & 290 & 214 & 180 & 288 \\
\hline White blood cells (4.5-11), $\times 10^{9} / 1$ & 6.7 & 13.5 & 7.9 & 7.4 \\
\hline Blood urea nitrogen $(8-25), \mathrm{mg} / \mathrm{dl}$ & 20 & 57 & 28 & 22 \\
\hline Creatinine $(0.6-1.5), \mathrm{mg} / \mathrm{dl}$ & 1.0 & 2.3 & 1.9 & 2.0 \\
\hline Sodium (135-145), mM & 136 & 138 & 141 & 142 \\
\hline Potassium $(3.4-4.8), \mathrm{mM}$ & 4.0 & 4.4 & 3.8 & 4.1 \\
\hline Chloride (100-108), mM & 100 & 110 & 109 & \\
\hline Calcium $(8.3-10.6), \mathrm{mg} / \mathrm{dl}$ & & 9.2 & & \\
\hline Lactate dehydrogenase (135-225), IU/l & & 1,311 & 570 & \\
\hline Haptoglobin $(30-200), \mathrm{mg} / \mathrm{dl}$ & & 5.5 & 11.2 & \\
\hline Total bilirubin $(0.0-1.0), \mathrm{mg} / \mathrm{dl}$ & 0.3 & 4.7 & 0.5 & \\
\hline Direct bilirubin $(0-0.4), \mathrm{mg} / \mathrm{dl}$ & 0.1 & 0.5 & 0.1 & \\
\hline$\gamma$-Glutamyl transpeptidase $(<38)$, IU/l & & 18 & & \\
\hline Alkaline phosphatase (37-108), IU/l & & 65 & & \\
\hline Alanine aminotransferase (10-40), IU/l & 37 & 61 & 26 & 30 \\
\hline Aspartate aminotransferase $(10-55), \mathrm{IU} / \mathrm{l}$ & 30 & 25 & 16 & 22 \\
\hline Creatine phosphokinase (60-400), IU/1 & & 130 & & \\
\hline Partial thromboplastin time $(10.8-13.4), \mathrm{s}$ & & 10.2 & & \\
\hline International normalized ratio $(0.8-1.2)$ & & 0.9 & & \\
\hline G6PD (4.6-13.5), IU/1012 erythrocytes & & 2.89 & & 4.8 \\
\hline
\end{tabular}

sequent induction of reactive oxygen species generation via effector caspase-3 activation.

The prooxidative effects of these compounds involve the generation of reactive oxygen species and phenoxyl radicals that attack proteins, DNA, and membrane lipids and trigger a cascade of events leading to cytotoxicity and eventual cell death. Galati et al. [6] found that these compounds caused hemolysis in vitro, with simultaneous oxidation of glutathione (GSH), hemoglobin, and polyphenols.

He et al. [7] suggested that G. biloba extracts may cause damage to red blood cells in vitro by increasing cell fragility, changing cellular morphology, and inducing GSH consumption and methemoglobin formation, particularly at high doses $(\geq 25 \mu \mathrm{g} / \mathrm{ml})$.

Kessler et al. [8] report that certain modifications in the structure of quercetin derivatives could make them function as a prooxidant instead of an antioxidant. Another study by Sahu and Gray [9] shows that the impairment of the nuclear antioxidant defense of GSH and glutathione S-transferase in a model system of isolated rat liver nuclei can lead to oxidative damage. The profound evidence may be limited in in vivo models.

The adequate in vivo dose corresponding to the in vitro dose is not known. However, some other authors do 
report a generation of a high concentration of hydroxyl radicals or hydrogen peroxide (at $100 \mu \mathrm{M}$ [10] or at 25$200 \mu \mathrm{M}[11])$.

G6PD deficiency, an X-linked disorder, is the most common enzymatic disorder of red blood cells in humans, affecting about 400 million people worldwide [12]. Most individuals with G6PD deficiency are asymptomatic throughout their lives and are unaware of their condition, even though it can cause severe, even fatal hemorrhage in some cases. One of the most frequent clinical manifestations of G6PD deficiency is acute hemolytic anemia, typically triggered by an exogenous agent. Several drugs have been implicated in this process. G. biloba, however, is not usually listed among them [13]. It should therefore be used with caution, especially in people with a family history of G6PD deficiency, to avoid possible complications or even death.

In our case, the patient was prescribed a single Cebonin injection (manufactured by Nang Kuang Pharmaceutical Company) in 5 doses. The product was not contaminated with other substances and was injected by a licensed nurse. According to the instructions, each milliliter contained $3.5 \mathrm{mg} \mathrm{G}$. biloba extract which was equivalent to $0.84 \mathrm{mg}$ Ginkgo flavonglycosides calculated as quercetin, kaempferol, isorhamnetin, and $0.21 \mathrm{mg}$ terpenlactone [14]. The excipients of the injection were sodium hydroxide, sorbitol and water, which, to the best of our knowledge, could not have caused the above-mentioned symptoms.
The patient did not eat fava beans or take other welldocumented drugs or chemicals associated with substantial hemolysis in patients with G6PD deficiency, such as aspirin, during or just prior to the 3-day period before admission [12]. No evidence of infection was found on the basis of the clinical symptoms and signs. Further, there are no reports of G6PD deficiency induced by nifedipine, telmisartan, or atenolol, which the patient was taking on a regular basis.

The temporal relationship between acute hemolysis and G. biloba injection was very strong in this case, with the patient noting symptoms within hours of the administration of the herbal medicine. The 10-day course of the disease was rapid and characterized by significant hemolysis in the context of G6PD deficiency. To our knowledge, this is the first case report of G. biloba-induced acute hemolytic anemia in G6PD deficiency in vivo.

In conclusion, more detailed mechanistic studies on the effects of the G. biloba leaf extract should be performed in vivo to evaluate the safety of ingesting high doses of this herbal remedy. It is important for clinicians to consider the possibility of herbal medicine-induced hemolytic anemia in the event of a substantial decrease in hemoglobin when other causes of blood cell loss have been excluded, especially in patients with a family history of G6PD deficiency.

\section{References}

$>1$ Bent S, Goldberg H, Padula A, Avins AL: Spontaneous bleeding associated with Ginkgo biloba: a case report and systematic review of the literature. J Gen Intern Med 2005;20:657661.

2 Rotblatt M, Ziment I: Evidence-Based Herbal Medicine. Philadelphia, Hanley \& Belfus, 2002.

$>3$ Pawlikowska-Pawlega B, Gruszecki WI, Misiak LE, Gawron A: The study of the quercetin action on human erythrocyte membranes. Biochem Pharmacol 2003;66:605-612.

4 Robaszkiewicz A, Balcerczyk A, Bartosz G: Antioxidative and prooxidative effects of quercetin on A549 cells. Cell Biol Int 2007;31: 1245-1250.

$\checkmark 5$ Shao ZH, Vanden Hoek TL, Xie J, Wojcik K, Chan KC, Li CQ, Hamann K, Qin Y, Schumacker PT, Becker LB, Yuan CS: Grape seed proanthocyanidins induce pro-oxidant toxicity in cardiomyocytes. Cardiovasc Toxicol 2003;3:331-339.
-6 Galati G, Sabzevari O, Wilson JX, O’Brien PJ: Prooxidant activity and cellular effects of the phenoxyl radicals of dietary flavonoids and other polyphenolics. Toxicology 2002;177: 91-104.

7 He J, Lin J, Li J, Zhang JH, Sun XM, Zeng CM: Dual effects of Ginkgo biloba leaf extract on human red blood cells. Basic Clin Pharmacol Toxicol 2009; 104:138-144.

$>8$ Kessler M, Ubeaud G, Jung L: Anti- and prooxidant activity of rutin and quercetin derivatives. J Pharm Pharmacol 2003;55:131-142.

-9 Sahu SC, Gray GC: Pro-oxidant activity of flavonoids: effects on glutathione and glutathione S-transferase in isolated rat liver nuclei. Cancer Lett 1996;104:193-196.

10 Laughton MJ, Halliwell B, Evans PJ, Hoult JR: Antioxidant and pro-oxidant actions of the plant phenolics quercetin, gossypol and myricetin. Effects on lipid peroxidation, hydroxyl radical generation and bleomycin-dependent damage to DNA. Biochem Pharmacol 1989;38:2859-2865.
11 Yen GC, Duh PD, Tsai HL, Huang SL: Prooxidative properties of flavonoids in human lymphocytes. Biosci Biotechnol Biochem 2003;67:1215-1222.

12 Cappellini MD, Fiorelli G: Glucose-6-phosphate dehydrogenase deficiency. Lancet 2008; 371:64-74.

13 Youngster I, Arcavi L, Schechmaster R, Akayzen Y, Popliski H, Shimonov J, Beig S, Berkovitch M: Medications and glucose6-phosphate dehydrogenase deficiency: an evidence-based review. Drug Saf 2010;33: 713-726.

14 Nang Kuang Pharmaceutical Co., Ltd. http:// nangkuang1963.en.gongchang.com (accessed July 28, 2012) 